\title{
Relationship Between Inactivation and Genome Damage of Human Enteroviruses Upon Treatment by $\mathrm{UV}_{254}$, Free Chlorine, and Ozone
}

\author{
Suzanne Young ${ }^{1} \cdot$ Jason Torrey ${ }^{1} \cdot$ Virginie Bachmann $^{1} \cdot \operatorname{Tamar}_{\text {Kohn }}{ }^{1}$ (I)
}

Received: 29 August 2019 / Accepted: 12 October 2019

(c) Springer Science+Business Media, LLC, part of Springer Nature 2019

\begin{abstract}
Quantitative PCR (qPCR) is a convenient tool for monitoring virus concentrations in water and wastewater treatment trains, though it only informs about virus presence, but not infectivity. This limitation can be overcome if the relationship between infectivity loss and genome decay induced by a given disinfectant is known. Here, we performed inactivation experiments using two human enteroviruses, Coxsackievirus B5 and Echovirus 11, with three disinfection methods: low-pressure ultraviolet light $\left(\mathrm{UV}_{254}\right)$, free chlorine (FC), and ozone. We compared the inactivation rates as measured by culturing to the decay rates of the whole genome, to evaluate the extent of qPCR-measurable genome damage as a function of inactivation. To determine genome damage, we used an approach that estimates damage across the full viral genome from the measured decay of multiple amplicons distributed across the viral genome. Correlations between inactivation and genome decay were observed for all viruses and all disinfection treatments, but results showed that even among closely related viruses, disinfection methods can damage the viral genome to different extents and that genome damage does not necessarily translate to inactivation. For both viruses, $\mathrm{UV}_{254}$ treatment had the closest relationship between inactivation and genome decay and with ozone, the rate of genome decay exceeded the inactivation rate. Finally, for FC, the ratios between methods were vastly different between viruses. This work provides the basis to relate qPCR measurements to infectivity loss and enables the establishment of molecular monitoring tools for assessing enterovirus inactivation during disinfection treatments of water and wastewater.
\end{abstract}

Keywords Enterovirus $\cdot$ Water treatment $\cdot$ Water reuse $\cdot$ Disinfection $\cdot$ Pathogen monitoring

\section{Introduction}

Advanced treatment technologies for wastewater and potable reuse systems require the study of human virus removal and inactivation. Accurate assessment of viral inactivation in such systems is critical for preventing the spread of disease and reducing public health risks, but deficiencies in accuracy and efficiency remain due to methodological challenges. Measuring inactivation after disinfection can be complicated because drinking water treatment processes are designed to remove pathogens with high efficiency, such that viruses are often present at very low concentrations in

Tamar Kohn

tamar.kohn@epfl.ch

1 Laboratory of Environmental Chemistry, School of Architecture, Civil and Environmental Engineering (ENAC), École Polytechnique Fédérale de Lausanne (EPFL), 1015 Lausanne, Switzerland finished water and large volumes must be concentrated for detection. Additionally, while cell culture methods are used to determine infectivity for many human viruses, these are often too time-consuming to measure virus concentrations in real-time, and too costly for large-scale implementation across industries. Developed cell culture systems are not yet available in the case of certain important viral pathogens, including human norovirus (Costantini et al. 2018; Ettayebi et al. 2016). Novel approaches are required to overcome these challenges, and investigating the use of quantitative PCR (qPCR) to assess viral infectivity may contribute to more rapid and accurate results.

qPCR has been widely accepted as a standard method to detect waterborne pathogens because of its ease of use and relative ease of the technique, although there are drawbacks. Most importantly, qPCR only measures the presence of a viral genome and does not provide information on the virus' ability to cause infection. This is because qPCR typically targets a single amplicon, but does not cover the entirety 
of the viral genome, such that any genome damage located outside the region targeted by the amplicon is missed. qPCR analysis thus overestimates the concentration of infective viruses (Pecson et al. 2009; Sobsey et al. 1998). However, qPCR can be used to estimate the residual virus infectivity after treatment $\left(\mathrm{C} / \mathrm{C}_{0}\right)$ if the reduction in the number of whole genome copies $\left(\mathrm{N} / \mathrm{N}_{0}\right)$, rather than a single amplicon, is considered. This can be achieved by either targeting a long genome segment (Simonet and Gantzer 2006) or multiple shorter amplicons by qPCR, followed by extrapolation of the measured damage to the entire genome, using the following equation (Eq. 1) (Pecson et al. 2011):

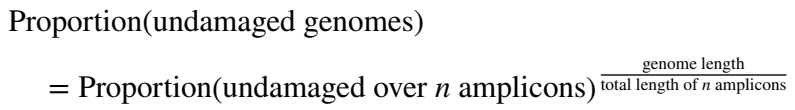

This approach has proven effective in the assessment of virus inactivation after treatment by $\mathrm{UV}_{254}$, where inactivation proceeds by a single-hit mechanism, and therefore, the inactivation rate is directly proportional to the genome decay rate (Pecson et al. 2011; Calgua et al. 2014; Rockey et al., submitted). Other disinfection methods, however, may induce multiple hits to the genome (e.g., free chlorine) (Zhong et al. 2017), or may act predominantly on viral proteins, thus causing little or no genome damage (e.g., heat treatment) (Wigginton et al. 2012). For these treatment processes, and in order for qPCR to provide a rapid assessment of genome damage as a proxy for infectivity, the relationship between infectivity and genome damage must be known.

In this study, we assessed the ratio between virus infectivity loss and genome damage of enteroviruses after different disinfection treatments. Enteroviruses are common, sometimes fatal, enteric human viruses, and are often associated with gastroenteritis, hand, foot, and mouth disease, myocarditis, and meningitis (Palacios and Oberste 2005). Enteroviruses have been detected in various stages of wastewater treatment, in the natural environment, and in sources of drinking water (Khetsuriani et al. 2006; Montazeri et al. 2015; Varughese et al. 2018). In the USA, enteroviruses are included in the priority list of contaminants to protect human health, the USEPA Contaminant Candidate List, and the Surface Water Treatment Rule stipulates a 4-log reduction in infective enteric viruses for the production of drinking water from surface water or groundwater under the direct influence of surface water (USEPA 1989). Wastewater treatment plants are currently not obligated by law to monitor human viruses in wastewater treatment effluent, but standard methods for enteroviruses have been developed to assess log removal and detection for research purposes in developing disinfectant dosing requirements (EPA Method 1615). Guidelines and performance targets have been developed for human viruses in direct and indirect potable reuse, ranging from 9-log to 12-log removal (WHO 2017). To ensure such stringent treatment requirements, a rapid monitoring tool to detect virus infectivity is instrumental.

In this work, we provide the basis for the development of a rapid, molecular monitoring tool to track enterovirus inactivation. Specifically, we assessed the change in genome integrity as a function of infectivity for two lab strains of human enteroviruses, the Echovirus 11 Gregory strain (E11) and Coxsackievirus B5 Faulkner strain (CVB5), in response to treatment by three common disinfection methods $\left(\mathrm{UV}_{254}\right.$, free chlorine (FC), ozonation). The multiple amplicon qPCR approach was used to estimate the extent of genome damage, and infectivity loss was measured by culture methods. We furthermore compared the ratio of genome damage: inactivation between the two viruses, to determine whether similar relationships are observed for both serotypes, or if each serotype needs to be assessed individually. Based on these results, an approach to estimate infectivity using a single qPCR amplicon is enabled.

\section{Materials and Methods}

\section{Virus Purification, Propagation, and Enumeration}

Concentrated stocks of CVB5-Faulkner (ATCC VR-185) and E11-Gregory (ATCC VR-41) were propagated by infecting confluent buffalo green monkey kidney cells (BGMK; kindly provided by the Spiez Laboratory, Switzerland). Before infection, cells were grown to confluence in culture flasks (TPP Techno Plastic Products, Trasadingen, Switzerland) with Minimum Essential Media (MEM; Gibco, Waltham, NY), amended with $1 \%$ penicillin and streptomycin and $10 \%$ fetal bovine serum (both Gibco, Life Technologies Corporation, Grand Island, NY), and incubated at $37{ }^{\circ} \mathrm{C}$ in $5 \%$ $\mathrm{CO}_{2}$ and $95 \%$ humidity in culture flasks (TPP Techno Plastic Products, Trasadingen, Switzerland). Cells were infected with previous cultured virus and incubated under the same conditions (with the exception that a $2 \%$ FBS media was used) until cytopathic effect (CPE) was observed. Infected cells were freeze-thawed three times for virus isolation and cellular disruption, and viruses were then concentrated and purified by filtration, centrifugation, and either polyethylene glycol and chloroform treatment as described elsewhere [CVB5; (Pecson et al. 2009)], or ultrafiltration and rinsing as described previously [E11; (Torrey et al. 2019)]. Aliquots of concentrated virus were stored at $-20{ }^{\circ} \mathrm{C}$ and brought to room temperature before use in inactivation experiments.

Viruses in stock solutions and samples were enumerated for infectivity by the most probable number (MPN) method, using confluent BGMK cells in 96-well plates as described above for virus propagation. Tenfold dilutions of samples were added to five replicate wells of confluent BGMK 
cells with 2\% FBS MEM, in 96-well plates (CELLSTAR, HUBERLAB). Cells were checked daily for CPE, and data were recorded after 5 days, using MPN statistics to determine the results (Kott 1966).

\section{Inactivation Experiments}

All experiments were performed with at least three biological replicates. Sterile magnetic stir bars were used in all experiments to ensure homogenous exposure of virus particles to disinfectants during the experiments. All samples were processed the same day for enumeration of infective viruses by the MPN assay and nucleic acid extraction. Detailed procedures for inactivation experiments using $\mathrm{UV}_{254}, \mathrm{FC}$, and ozonation are described below.

$\mathrm{UV}_{254}$ disinfection experiments were performed using a custom-made light box equipped with a low-pressure $18 \mathrm{~W}$ UV-C lamp (253.7 nm, model TUV T8 Philips) in a quasiparallel beam setup, with a mechanical sliding cover to control timing of exposure to light. Sides of beakers were covered in aluminum foil to limit light exposure to directly from above. The irradiance from the collimated beam, determined by KI actinometry (Rahn et al. 2006), was $0.15 \mathrm{~mW} \mathrm{~cm} \mathrm{~cm}^{-2}$. Briefly, beakers with $3 \mathrm{~mL}$ of phosphate-buffered solution (PBS; $5 \mathrm{mM} \mathrm{Na}_{2} \mathrm{HPO}_{4}$ (99\%, Acros), $10 \mathrm{mM} \mathrm{NaCl}$ (99.5\%, Acros), $\mathrm{pH} 7.5)$, and $100 \mu \mathrm{L}$ of concentrated virus $\left(10^{7}-10^{8}\right.$ $\mathrm{MPN} / \mathrm{mL}$ ) were placed on a magnetic stir plate inside the light box and exposed to $\mathrm{UV}_{254}$. Samples were collected at 60 -s time intervals in $100 \mu \mathrm{L}$ volumes and placed in sterile PBS at 1:10 dilutions. $100 \mu \mathrm{L}$ of the diluted sample was added to $900 \mu \mathrm{L}$ of MEM for MPN assay processing, and $200 \mu \mathrm{L}$ was used for nucleic acid extraction.

FC experiments were performed in chlorine-free glassware prepared as described previously (Torrey et al. 2019). A concentrated solution of FC was created by adding $6 \mu \mathrm{L}$ of concentrated bleach (Javel 13-14\% sodium hypochlorite, Reactolab SA) to $50 \mathrm{~mL}$ of PBS. The concentrated FC stock was then diluted in PBS to experimental FC concentrations ranging from 1 to $3 \mathrm{mg} / \mathrm{L}$ as $\mathrm{HOCl}$. The experimental solutions were spiked with $100 \mu \mathrm{L}$ of viral stock solutions $\left(10^{7}-10^{8} \mathrm{MPN} / \mathrm{mL}\right) .30-\mu \mathrm{L}$ samples were taken at 15- to 30 -s intervals, were added to $270 \mu \mathrm{L}$ of PBS amended with a sevenfold excess concentration of sodium thiosulfate (Sigma-Aldrich) to quench the residual chlorine, and were then processed for infectivity and nucleic acid extraction as described above. FC concentrations were measured at the start and end of each experiment by the Diethyl-p-phenylene diamine (DPD) method (APHA 1998), and were found to be stable. Indicator buffer solutions used for DPD colorimetry were a phosphate solution containing $\mathrm{Na}_{2} \mathrm{HPO}_{4}$ (Acros Organics), $\mathrm{KH}_{2} \mathrm{PO}_{4}$ (Sigma-Aldrich), and Ethylenediaminetetraacetic acid (EDTA; Carl Roth $\mathrm{GmbH}+\mathrm{Co} . \mathrm{KG}$ ), and a DPD solution containing DPD oxalate (Acros Organics), EDTA, and $\mathrm{H}_{2} \mathrm{SO}_{4}$ (Merck KGaA).

Ozonation experiments were performed according to previously described methods (Wolf et al. 2018). Briefly, ozone was produced by an ozone generator (Model CMG 3-3 or CMG 3-5, Innovatec, Rheinbach, Germany) from pure oxygen (Carbagaz) and bubbled into 1L of Barnstead Nanopure (Thermofisher)/Milli-Q (Millipore) water to make a stock solution of approximately $1 \mathrm{mM} \mathrm{O}_{3}$. Then, the ozone stock solution was injected into sealed glass reactors containing $45 \mathrm{~mL}$ of an experimental solution containing PBS with a lowered $\mathrm{pH}$ (6.5 instead of 7.5), viral inoculum added to a final concentration of $10^{7} \mathrm{MPN} / \mathrm{mL}, 20 \mathrm{mM}$ tert-butanol (Sigma-Aldrich) to quench hydroxyl radicals, and trans-cinnamic acid (Sigma-Aldrich) at concentrations between 120 and $180 \mu \mathrm{M}$ to control ozone demand. Multiple solutions of varying $\mathrm{O}_{3}$ :cinnamic acid ratios were made to achieve estimated ozone exposures of $3.4 \times 10^{-4}-4.4 \times 10^{-3} \mathrm{mg} \mathrm{min} / \mathrm{L}$ (Wolf et al. 2018). Reactors were placed on a stir plate for 2 min to allow all ozone to be consumed. Then, a $100-\mu \mathrm{L}$ sample was placed in $900 \mu \mathrm{L}$ of PBS and was processed for MPN analysis and nucleic acid extraction as described above.

Inactivation kinetics were modeled as a first-order process with respect to disinfectant exposure (Eq. 2):

$\ln \left(\frac{C}{C_{0}}\right)=-k_{\text {inact }} \cdot \int_{0}^{t} D(t) \mathrm{d} t$

where $\mathrm{C}$ and $\mathrm{C}_{0}$ are the infective virus concentrations (determined by culturing) after and prior to disinfection treatment, respectively, $k_{\text {inact }}\left(\mathrm{mJ}^{-1} \mathrm{~cm}^{2}\right.$ or $\left.\mathrm{mg}^{-1} \mathrm{~L} \mathrm{~min}^{-1}\right)$ is the inactivation rate constant, and $\mathrm{D}(\mathrm{t})$ is the disinfectant concentration (or irradiance) at a given exposure time $t$.

\section{qPCR Analyses}

For CVB5, RNA extraction was performed using PureLink Viral RNA/DNA Mini Kits (Invitrogen). For E11, Amicon centrifugal filters (MWCO $100 \mathrm{kDa}$ ) were used to first concentrate the samples before extracting RNA using the QIAamp Viral RNA Mini kit (Qiagen). All dilution and concentration steps were accounted for in calculations. qPCR assays were performed using SYBR Green reagents in a One-step PrimeScript RT-PCR kit for real-time RT-PCR (Takara), with the primers listed in Table 1 (Microsynth). For all assays, a standard MasterMix was used following Takara guidelines for enzymes and reagents, for a total volume of $15 \mu \mathrm{L}$ with $3 \mu \mathrm{L}$ of template sample, using primers at $0.2 \mu \mathrm{M}$ concentrations. All samples from inactivation experiments were run in duplicate on a MIC (Magnetic Induction 
Table 1 Primers targeting multiple amplicons for two enteroviruses, Echovirus 11 (E11) and Coxsackievirus B5 (CVB5), including target regions for each primer set

\begin{tabular}{|c|c|c|c|}
\hline Virus & Primer set $\left(5^{\prime} \rightarrow 3^{\prime}\right)$ & Genome region/peptide & Length (bases) \\
\hline \multirow[t]{5}{*}{ E11 (7438 bases) } & $\begin{array}{l}\text { 1F: ACTTTGGGTGTCCGTGTTTC } \\
\text { 1R: TACTCAGGCCATCGACCATAC }\end{array}$ & VP4/VP2 & 531 \\
\hline & $\begin{array}{l}\text { 2F: TGGGAGGATACCACACAACC } \\
\text { 2R: AGTTCACCGTGGATGCATTT }\end{array}$ & VP1 & 569 \\
\hline & $\begin{array}{l}\text { 3F: GACTCAAGCAGCTCCCTCTG } \\
\text { 3R: GGGCCCTACTATCTGACACG }\end{array}$ & $2 \mathrm{C}$ & 567 \\
\hline & $\begin{array}{l}\text { 4F: CATGTCCACCGGTAAGGTCT } \\
\text { 4R: TAGATCCCTGGTCCTCCTTG }\end{array}$ & $3 \mathrm{C} / 3 \mathrm{D}$ & 511 \\
\hline & Genome coverage & & $2176(29 \%)$ \\
\hline \multirow[t]{8}{*}{ CVB5 (7400 bases) } & $\begin{array}{l}\text { 1F:ATGGAAATTGCGGAGTGTT } \\
\text { 1R:AATTCCGCAAATAGGCAAGA }\end{array}$ & 5'UTR/VP4 & 605 \\
\hline & $\begin{array}{l}\text { 2F:CTACTTGAGGGACGATGAA } \\
\text { 2R:ATGTACCGATCACAGTGACA }\end{array}$ & VP2 & 613 \\
\hline & $\begin{array}{l}\text { 3F:AGATTGCGGAGGTGGAT } \\
\text { 3R:AGATTTTGTGCTTTGTGTCA }\end{array}$ & VP3 & 512 \\
\hline & $\begin{array}{l}\text { 4F:AGATCCGCATGTGTTTACTACA } \\
\text { 4R:ATGATGGATGGGCTAGATTTGA }\end{array}$ & VP1 & 398 \\
\hline & $\begin{array}{l}\text { 5F:ACTACCGGAGTGTATTTCTGT } \\
\text { 5R:ACTGGTTATTGTGGTAAGAAATCA }\end{array}$ & $2 \mathrm{~A}$ & 455 \\
\hline & $\begin{array}{l}\text { 6F:AGAAAGGCATCTTGTTCACTT } \\
\text { 6R:TTGGTTCCTGAGGTCAACT }\end{array}$ & $2 \mathrm{C} / 3 \mathrm{~A}$ & 513 \\
\hline & $\begin{array}{l}\text { 7F:TTGAGGAGGCCATATTCTCAA } \\
\text { 7R:TTTGGAGTAAAATACCGGTGAT }\end{array}$ & $3 \mathrm{D}$ & 511 \\
\hline & Genome coverage & & $3607(49 \%)$ \\
\hline
\end{tabular}

Cycles) qPCR Machine (Biomolecular Systems). Standard curves were run along with samples and were based on tenfold dilutions of viral RNA from concentrated viral stocks previously extracted using the kits given above. All qPCR assays used the same thermal cycling conditions, with an initial hold of $20 \mathrm{~min}$ at $42{ }^{\circ} \mathrm{C}$, followed by a hold of $15 \mathrm{~s}$ at $95^{\circ} \mathrm{C}$, then 40 cycles of $15 \mathrm{~s}$ at $95^{\circ} \mathrm{C}, 30 \mathrm{~s}$ at $55^{\circ} \mathrm{C}$, and $20 \mathrm{~s}$ at $72{ }^{\circ} \mathrm{C}$. qPCR signals were converted to concentrations of gene copies using the Mic software (Version 1.4).

\section{Assessment of Genome Damage}

To estimate genome damage caused by the different disinfectants, multiple amplicons were targeted for each virus (Table 1). For CVB5 (accession AF114383.1), seven amplicons representing approximately $49 \%$ of the full genome (7400 bases) were used. For E11 (accession X80059.1), the four amplicons used to encompass approximately $29 \%$ genome coverage ( 7438 bases). The proportion of intact (undamaged) genomes after disinfection treatment was estimated based on the measured intact amplicon fractions, according to Eq. 3:

$\ln \left(\frac{N}{N_{0}}\right)=\frac{\text { Genome length }}{\text { Total length of } \mathrm{n} \text { amplicons }} \cdot \ln \left(\prod_{i=1}^{n} \frac{x_{i}}{x_{0, i}}\right)$ where $N$ and $N_{0}$ are the concentrations of intact genomes after and prior to disinfectant treatment, $\mathrm{n}$ is the number of amplicons, and $x_{\mathrm{i}}$ and $x_{0, \mathrm{i}}$ are the concentrations of intact amplicon $\mathrm{i}$ after and prior to disinfectant treatment, respectively, measured by qPCR (Pecson et al. 2011). Finally, the genome decay rate $k_{\text {genome }}\left(\mathrm{mJ}^{-1} \mathrm{~cm}^{2}\right.$ or $\left.\mathrm{mg}^{-1} \mathrm{~L} \mathrm{~min}{ }^{-1}\right)$ caused by each disinfectant was determined as a first-order process with respect to disinfectant exposure, according to Eq. 4:

$\ln \left(\frac{N}{N_{0}}\right)=-k_{\text {genome }} \cdot \int_{0}^{t} D(t) \mathrm{d} t$

\section{Data Analysis}

Correlation analysis was conducted in Excel to determine the degree of correlation between genome damage and infectivity loss for each combination of virus and disinfectant. ANCOVA was performed in Excel to compare the inactivation kinetics (determined by culturing) and genome decay kinetics (determined by qPCR) for each combination of virus and disinfectant, as well as the ratio of inactivation: genome damage across viruses and disinfectants. The threshold $P$-value for statistical significance was set to 0.05 . 

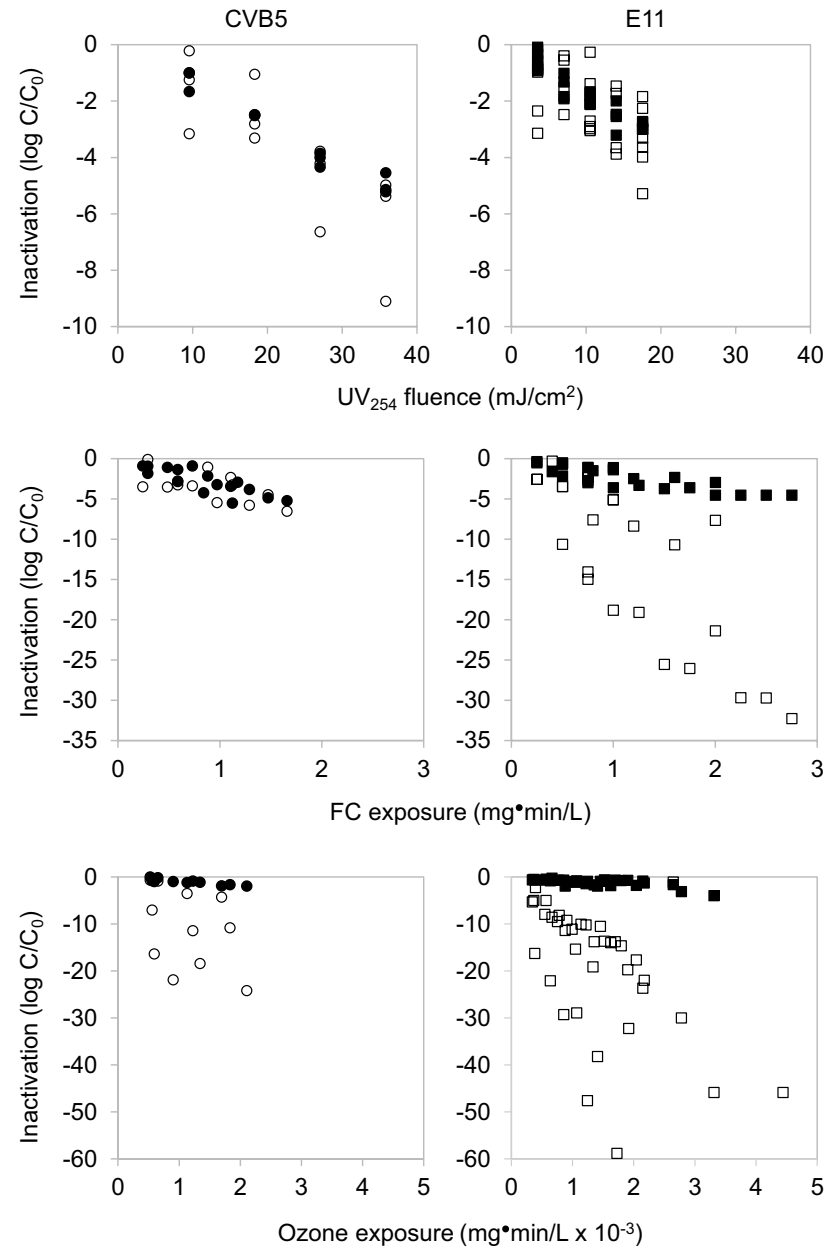

Fig. 1 Inactivation of Coxsackievirus B5 Faulkner (left column) showing loss as measured by MPN (filled circles) and genome damage (open circles), and of Echovirus 11 Gregory (right column) showing loss as measured by MPN (filled squares) and genome damage (open squares). Inactivation data are presented on a $\log _{10}$ scale for readability. Note the difference in scale on the y-axis for each disinfectant

\section{Results}

Inactivation curves were established for two human enteroviruses, CVB5 and E11, using three disinfection methods: $\mathrm{UV}_{254}, \mathrm{FC}$, and ozonation (Fig. 1). Infectivity loss and amplicon decay were determined at different disinfectant exposures, and genome decay was estimated based on Eq. 3. As is evident from Fig. 1, the data on genome decay are associated with scatter. This scatter arises from the extrapolation method used to estimate damage across the whole genome from the measured decay of amplicons (Eq. 3). Even a small error in the measured amplicon decay rapidly becomes magnified when extrapolated to the whole genome. However, assuming that the qPCR measurement errors are randomly distributed, the kinetic analysis applied to the entirety of data points for a given combination of virus and disinfectant (Eq. 4) should nevertheless yield a reasonable estimate of the genome decay rate.

Inactivation and genome decay rate constants are shown in Table 2. Inactivation proceeded at comparable rates (within a factor of 2) for both viruses for a given treatment considered. Genome decay kinetics were similar for both viruses for $\mathrm{UV}_{254}$ and ozone, but divergent for $\mathrm{FC}$, with E11 exhibiting more rapid genome decay compared to CVB5. When comparing inactivation and genome decay kinetics for a single virus and disinfectant, similarity was observed within all disinfectant types for CVB5, with no significant differences between inactivation and genome decay rates. In contrast, statistically significant differences between inactivation and genome decay were observed for FC and ozone for E11 (ANCOVA; $P<0.05$; indicated in italic font in Table 2).

For a given disinfectant dose, amplicon decay was relatively uniform across the entire genome for inactivation by FC. In contrast, variation between amplicons was observed for inactivation by $\mathrm{UV}_{254}$ (Fig. 2). This
Table 2 Inactivation rate constants $\left(k_{\text {inact }}\right)$ and genome decay rate constants $\left(k_{\text {genome }}\right.$ for each disinfectant and virus, ratio of genome damage to infectivity loss and corresponding correlation coefficient $(\mathrm{R})$

\begin{tabular}{|c|c|c|c|c|c|}
\hline \multirow[t]{2}{*}{ Virus } & \multirow[t]{2}{*}{ Disinfectant } & \multicolumn{2}{|l|}{ Kinetic constants } & \multicolumn{2}{|c|}{$\begin{array}{l}\text { Comparison genome } \\
\text { decay vs. infectivity loss }\end{array}$} \\
\hline & & $\begin{array}{l}k_{\text {inact }}\left(\mathrm{mJ}^{-1} \mathrm{~cm}^{2} \text { or }\right. \\
\left.\mathrm{mg}^{-1} \mathrm{~L} \mathrm{~min}^{-1}\right)\end{array}$ & $\begin{array}{l}k_{\text {genome }}\left(\mathrm{mJ}^{-1} \mathrm{~cm}^{2} \text { or }\right. \\
\left.\mathrm{mg}^{-1} \mathrm{~L} \mathrm{~min}^{-1}\right)\end{array}$ & $\begin{array}{l}\text { Ratio }(\ln (\mathrm{N} / \\
\mathrm{N} 0): \ln (\mathrm{C} / \mathrm{C} 0))\end{array}$ & $R$ \\
\hline \multirow[t]{3}{*}{ CVB5 } & $\mathrm{UV}_{254}$ & $0.34 \pm 0.05$ & $0.46 \pm 0.23$ & $1.3 \pm 0.7$ & 0.81 \\
\hline & $\mathrm{FC}$ & $7.2 \pm 2.7$ & $6.1 \pm 6.0$ & $0.5 \pm 0.8^{*}$ & 0.33 \\
\hline & $\mathrm{O}_{3}$ & $2308 \pm 942$ & $13,877 \pm 24,078$ & $6.4 \pm 8.8$ & 0.48 \\
\hline \multirow[t]{3}{*}{ E11 } & $\mathrm{UV}_{254}$ & $0.38 \pm 0.06$ & $0.35 \pm 0.2$ & $0.7 \pm 0.5$ & 0.46 \\
\hline & $\mathrm{FC}$ & $3.8 \pm 1.1$ & $26.6 \pm 8.3$ & $6.7 \pm 1.2^{*}$ & 0.93 \\
\hline & $\mathrm{O}_{3}$ & $1978 \pm 600$ & $19,662 \pm 10,533$ & $6.8 \pm 4.1$ & 0.49 \\
\hline
\end{tabular}

Values in italic indicate statistically significant differences between $k_{\text {inact }}$ and $k_{\text {genome }}$ (ANCOVA; $P<0.05$ ) for a given combination of virus and disinfectant. Asterisks indicate ratios of genome damage to infectivity loss that differ significantly between viruses (ANCOVA; $P<0.05$ ). Errors indicate $95 \%$ confidence intervals 


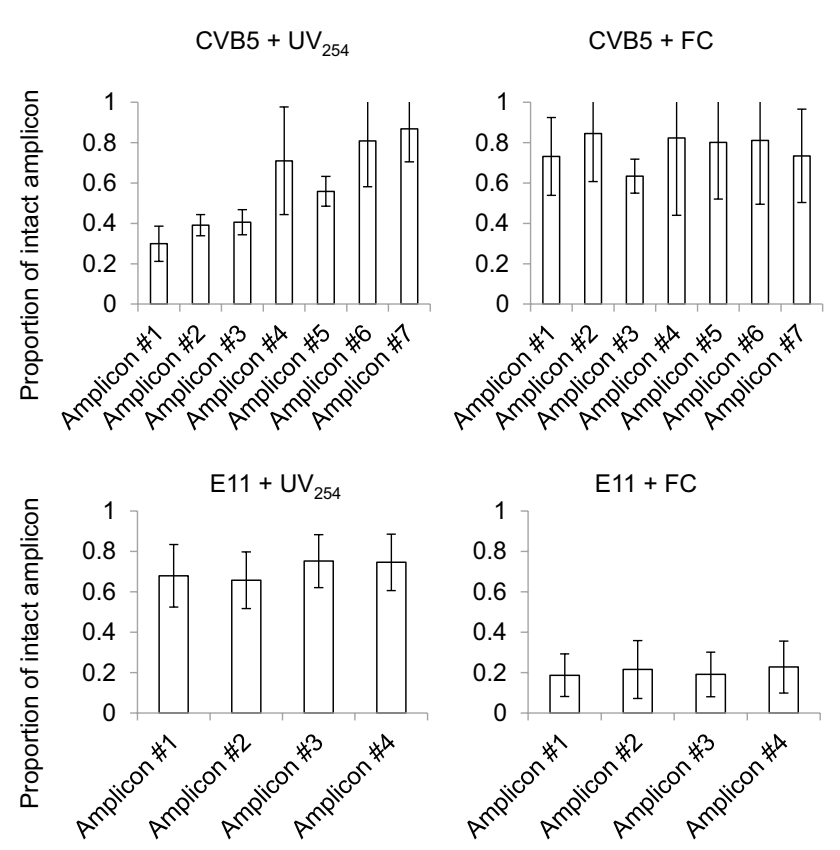

Fig. 2 Amplicon decay at one exposure of $\mathrm{UV}_{254}\left(18 \mathrm{~mJ} / \mathrm{cm}^{2}\right.$ with CVB5 and $10.5 \mathrm{~mJ} / \mathrm{cm}^{2}$ with $\left.\mathrm{EV}\right)$ and $\mathrm{FC}(0.75 \mathrm{mg} \mathrm{min} / \mathrm{L}$ with CVB5 and $0.8 \mathrm{mg} \mathrm{min} / \mathrm{L}$ with E11) for all target amplicons. Error bars indicate standard deviations based on at least 3 replicates

variability is consistent with previous studies, where differences in amplicon decay were found (Pecson et al. 2011; Rockey et al., submitted), depending on amplicon length and position. No assessment could be made regarding the uniformity of amplicon decay by ozone, because of the large scatter in the data (not shown).

We evaluated inactivation vs. genome damage for each virus and disinfectant (Fig. 3). Despite the scatter in genome decay data discussed above, correlation coefficients could be derived for all viruses and treatments. For CVB5, the correlation was strong for $\mathrm{UV}_{254}$ $(R=0.81 ; P<0.05)$. Weaker correlations were found for FC $(R=0.33 ; P=0.20)$ and ozone $(R=0.48 ; P=0.13)$ and were only significant at the $80 \%$ and $87 \%$ confidence level, respectively. Inactivation and genome damage were also correlated for E11, with FC exhibiting the strongest correlation $(R=0.93 ; P<0.05)$, followed by ozone $(R=0.49 ; P<0.05)$ and $\mathrm{UV}_{254}(R=0.46 ; P<0.05)$. The ratios between infectivity loss and genome decay (corresponding to the slopes of $\ln \left(C / C_{0}\right)$ vs. $\ln \left(N / N_{0}\right)$; Fig. 3 and Table 2) were similar between viruses and not different from 1 for inactivation by $\mathrm{UV}_{254}$. For ozone, the ratio was higher but not significantly different between the two viruses. In contrast, the ratios differed significantly between CVB5 and E11 for inactivation by FC, with a ratio not different from 1 for CVB5, but $>>1$ for E11 (ANCOVA; $P<0.05$; indicated by an asterisk in Table 2 ).

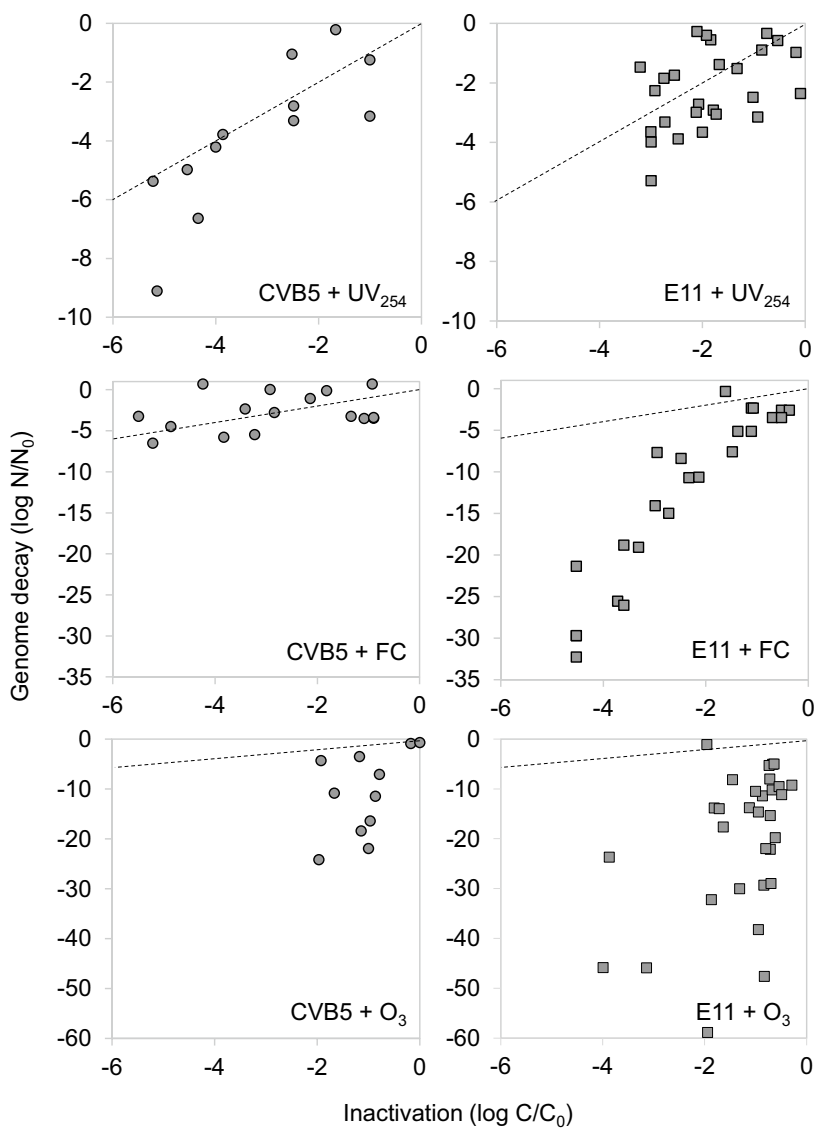

Fig. 3 Correlation of two methods for assessing inactivation (infectivity assay and genome damage) of CVB5 (left column) and E11 (right column) by $\mathrm{UV}_{254}$, chlorination, and ozonation. Dashed lines represent a 1:1 relationship between infectivity loss and genome damage. Data are presented on a $\log _{10}$ scale for readability. Note the difference in scale on the $y$-axis for each disinfectant

\section{Discussion}

All of the disinfection treatments investigated herein resulted in progressive genome damage with increasing disinfectant exposure. However, the extent of genome damage per unit inactivation differed between disinfectants. Ratios for genome damage:infectivity loss represent how closely genome damage - as measurable by qPCR - tracks inactivation. A ratio of 1 would indicate equal extents of genome damage and infectivity loss, consistent with a model where each hit to the genome causes inactivation. In contrast, a ratio $>1$ suggests that multiple hits to the genome are needed to cause an inactivation event.

Exposure to $\mathrm{UV}_{254}$ resulted in genome degradation that matched the decrease in infectivity. This supports what is known about UV inactivation mechanisms, causing genomic lesions that result in inactivation (Beck et al. 2016; Simonet and Gantzer 2006; Calgua et al. 2014; Pecson et al. 2011). Furthermore, genome decay rates were similar for both 
viruses, consistent with previous findings that different enterovirus serotypes are inactivated by $\mathrm{UV}_{254}$ at comparable rates (Meister et al. 2018).

Similar inactivation rates for CVB5 and E11 have also been reported for inactivation by ozone (Wolf et al. 2018). Consistent with this finding, the ratio between genome decay and inactivation was also similar for these two serotypes. For both viruses, genome decay outcompeted inactivation by a factor of $>6$, though there was high scatter in the data. This high ratio indicates that reactions between ozone and viral RNA prevent the PCR enzymes from amplifying the viral RNA, but do not prevent the host cells from replicating the genome and producing viral progeny. The majority of ozone reactions with viral RNA thus do not constitute inactivating events, though they do lead to an accumulation of RNA damage that is detectable by qPCR.

In contrast to $\mathrm{UV}_{254}$ and ozone, $\mathrm{FC}$ caused differing effects in the two viruses considered, with E11 exhibiting greater genome damage per unit of inactivation compared to CVB5. Previous work demonstrated that both viral genome and proteins in E11 are damaged by FC (Zhong et al. 2017), but that protein damage is more significant in terms of loss of functionality (Torrey et al. 2019). The extensive genome damage accumulated by E11, while detectable by qPCR, is thus likely a byproduct of FC treatment, rather than the primary cause of inactivation. Comparable data for CVB5 regarding mechanisms of inactivation are not available in previous literature. However, CVB5 has been found to be more resistant to FC compared to other enterovirus serotypes (Payment et al. 1985; Meister et al. 2018). This resistance may in part arise from a more stable protein capsid, such that FC may be prevented from entering the capsid and causing genome degradation. This hypothesis, however, remains to be confirmed.

All treatments and viruses studied herein exhibited correlations of inactivation measured by culturing and genome damage. This suggests that using a calculated ratio of genome decay to infectivity loss can be utilized and applied to monitor virus inactivation during water and wastewater disinfection. Specifically, we here provide ratios to translate reductions in entire genomes $\left(\log N / N_{0}\right)$ to infectivity loss $\left(\log C / C_{0}\right)$. Based on the data set of two serotypes provided herein, it appears feasible that ratios determined for UV and ozone may apply across different enteroviruses. In contrast, for $\mathrm{FC}$, ratios need to be determined individually for each serotype of interest.

Given that measurement of the entire genome by qPCR is laborious, a simpler approach could be pursued using a single amplicon only. A single amplicon would degrade less readily than the full genome during disinfection treatment, because its smaller size renders it less likely to be hit during disinfection treatment. In addition, as shown herein and in previous studies (Pecson et al. 2011; Rockey et al., submitted), the extent of decay in response to disinfectants varies across the genome, in particular for $\mathrm{UV}_{254}$. For a single amplicon approach to be successful, the design of the amplicon thus requires additional research to identify parts of the genome that are most likely to be damaged by the disinfectant of interest, and the decay rate of the amplicon selected would then have to be specifically calibrated against the corresponding inactivation. Finally, an ideal amplicon would cover a genome region that is conserved across strains, or even serotypes. Despite the design effort involved, the data presented herein indicates that the single amplicon approach may be feasible, in particular in the case of ozone treatment or FC treatment of E11. Because these treatments led to extensive genome damage per unit of inactivation, a single amplicon may accumulate sufficient damage to allow detection by qPCR, even at low levels of inactivation. The use of a single amplicon in conjunction with $\mathrm{UV}_{254}$ treatment would be more challenging, in particular at low levels of inactivation, because of the low likelihood of a single amplicon to incur genome damage.

A recent review (Gerba et al. 2018) included the recommendation to use ratios similar to this approach when attempting to reduce uncertainty in measuring viral reduction through water treatment, particularly in untreated wastewater, and to obtain a better assessment of initial infectivity. The results presented here further support the notion that molecular methods are useful for assessing viral inactivation after water treatment, with the caveat that variability among viruses and treatment applications should be considered. Furthermore, the ratios reported herein remain to be confirmed for different water types. Future studies that expand on these results can contribute more effective monitoring tools and regulation of risks to human health and enforcing and maintaining rigorous standards for water treatment and reuse.

Acknowledgements This research was supported by the Water Environment and Reuse Foundation (WERF; Project Number 15-07), the Swiss National Science Foundation (Project Number 205321_169615), and EPFL discretionary funds. We thank Krista Wigginton for valuable input and discussion.

\section{References}

APHA. (1998). Standard methods for the examination of water and waste water (20th ed.). Washington, D.C: American Public Health Association.

Beck, S. E., Rodriguez, R. A., Hawkins, M. A., Hargy, T. M., Larason, T. C., \& Linden, K. G. (2016). Comparison of UV-induced inactivation and RNA damage in MS2 Phage across the germicidal UV spectrum. Applied and Environment Microbiology, 82(5), 1468. https://doi.org/10.1128/AEM.02773-15.

Calgua, B., Carratalà, A., Guerrero-Latorre, L., de Abreu Corrêa, A., Kohn, T., Sommer, R., et al. (2014). UVC inactivation of dsDNA and ssRNA viruses in water: UV fluences and a qPCR-based 
approach to evaluate decay on viral infectivity. Food Environmental Virology, 6(4), 260-268.

Costantini, V., Morantz, E. K., Browne, H., Ettayebi, K., Zeng, X. L., Atmar, R. L., et al. (2018). Human norovirus replication in human intestinal enteroids as model to evaluate virus inactivation. Emerging Infectious Diseases, 24(8), 1453-1464. https:// doi.org/10.3201/eid2408.180126.

Ettayebi, K., Crawford, S. E., Murakami, K., Broughman, J. R., Karandikar, U., Tenge, V. R., et al. (2016). Replication of human noroviruses in stem cell-derived human enteroids. Science, 353(6306), 1387-1393. https://doi.org/10.1126/science.aaf5211.

Gerba, C. P., Betancourt, W. Q., Kitajima, M., \& Rock, C. M. (2018). Reducing uncertainty in estimating virus reduction by advanced water treatment processes. Water Research, 133, 282-288. https ://doi.org/10.1016/j.watres.2018.01.044.

Khetsuriani, N., Lamonte-Fowlkes, A., Oberst, S., \& Pallansch, M. A. (2006). Enterovirus surveillance-United States, 1970-2005. MMWR Surveillance Summary, 55(8), 1-20.

Kott, Y. (1966). Estimation of low numbers of Escherichia coli bacteriophage by use of the most probable number method. Applied and Environment Microbiology, 14(2), 141-144.

Meister, S., Verbyla, M. E., Klinger, M., \& Kohn, T. (2018). Variability in disinfection resistance between currently circulating enterovirus B serotypes and strains. Environmental Science and Technology, 52(6), 3696-3705. https://doi.org/10.1021/acs.est.8b00851.

Montazeri, N., Goettert, D., Achberger, E. C., Johnson, C. N., Prinyawiwatkul, W., \& Janes, M. E. (2015). Pathogenic enteric viruses and microbial indicators during secondary treatment of municipal wastewater. Applied and Environment Microbiology, 81(18), 6436-6445. https://doi.org/10.1128/aem.01218-15.

Palacios, G., \& Oberste, M. S. (2005). Enteroviruses as agents of emerging infectious diseases. Journal of Neurovirology, 11(5), 424-433. https://doi.org/10.1080/13550280591002531.

Payment, P., Tremblay, M., \& Trudel, M. (1985). Relative resistance to chlorine of poliovirus and coxsackievirus isolates from environmental sources and drinking water. Applied and Environmental Microbiology, 49(4), 981-983.

Pecson, B. M., Ackermann, M., \& Kohn, T. (2011). Framework for using quantitative PCR as a nonculture based method to estimate virus infectivity. Environmental Science and Technology, 45(6), 2257-2263. https://doi.org/10.1021/es103488e.

Pecson, B. M., Martin, L. V., \& Kohn, T. (2009). Quantitative PCR for determining the infectivity of bacteriophage MS2 upon inactivation by heat, UV-B radiation, and singlet oxygen: Advantages and limitations of an enzymatic treatment to reduce false-positive results. Applied and Environment Microbiology, 75(17), 55445554. https://doi.org/10.1128/AEM.00425-09.
Rahn, R. O., Bolton, J., \& Stefan, M. I. (2006). The iodide/iodate actinometer in UV disinfection: Determination of the fluence rate distribution in UV reactors. Photochemistry and Photobiology, 82(2), 611-615. https://doi.org/10.1562/2005-06-10-RN-570.

Rockey, N., Young, S., Pecson, B., Wobus, C., Raskin, L., Kohn, T., Wigginton, K. (submitted). Genome-wide PCR approach reveals susceptibility of human norovirus to UV disinfection.

Simonet, J., \& Gantzer, C. (2006). Inactivation of poliovirus 1 and F-specific RNA phages and degradation of their genomes by UV irradiation at 254 nanometers. Applied and Environment Microbiology, 72(12), 7671-7677.

Sobsey, M., Battigelli, D., Shin, G.-A., \& Newland, S. (1998). RT-PCR amplification detects inactivated viruses in water and wastewater. Water Science and Technology, 38(12), 91-94.

Torrey, J., von Gunten, U., \& Kohn, T. (2019). Differences in viral disinfection mechanisms as revealed by quantitative transfection of Echovirus 11 genomes. Applied and Environment Microbiology. https://doi.org/10.1128/aem.00961-19.

USEPA. (1989). National primary drinking water regulations: Filtration, disinfection; turbidity, giardia lamblia, viruses, legionella and heterotrophic bacteria; final rule. In USEPA (Ed.), (Vol. Federal Register 54, 124, 27486).

Varughese, E. A., Brinkman, N. E., Anneken, E. M., Cashdollar, J. L., Fout, G. S., Furlong, E. T., et al. (2018). Estimating virus occurrence using Bayesian modeling in multiple drinking water systems of the United States. Science of the Total Environment, 619-620, 1330-1339. https://doi.org/10.1016/j.scitotenv.2017.10.267.

WHO. (2017). Potable reuse: Guidance for producing safe drinkingwater. Geneva: World Health Organization.

Wigginton, K. R., Pecson, B. M., Sigstam, T., Bosshard, F., \& Kohn, T. (2012). Virus inactivation mechanisms: Impact of disinfectants on virus function and structural integrity. Environmental Science and Technology, 46(21), 12069-12078. https://doi.org/10.1021/ es3029473.

Wolf, C., von Gunten, U., \& Kohn, T. (2018). Kinetics of inactivation of waterborne enteric viruses by ozone. Environmental Science and Technology, 52(4), 2170-2177.

Zhong, Q., Carratalà, A., Ossola, R., Bachmann, V., \& Kohn, T. (2017). Cross-resistance of UV-or chlorine dioxide-resistant echovirus 11 to other disinfectants. Frontiers Microbiology, 8, 1928.

Publisher's Note Springer Nature remains neutral with regard to jurisdictional claims in published maps and institutional affiliations. 